\title{
Teacher-Child Interactions During Mathematic Activities in a Preschool Class
}

\author{
Norela Mohamed Shah, Zahyah Hanafi \\ City University College of Science and Technology, College of Arts and Sciences, University Utara Malaysia \\ Corresponding e-mail: norelamatsah@ymail.com
}

\begin{abstract}
This study examines the interactions between two preschool teachers and six years old children from two different classes during Mathematic activities. This paper describes what happens when the teachers and children interact and how the interactions help develop the process of learning Mathematic in class. According to Vygotsky theory, the Zone Proximal Development, explains whether a child can perform and accomplished better with the support or guidance from an older child, peer or an adult. Learning is said to occur during this collaborative interaction and dialogue. The data is captured through observation, using video recording during the Mathematic activities in class. A purposeful sampling of children and their Mathematic teachers were selected from each class. One class had eight (8) children and the other had six (6). The findings indicate that appropriate response; children's taking-time to notice or response to and what children are going to answer or reply exhibits their learning. The data revealed that teachers tend to control most of the interactions in a teacherguided Mathematic activity. Accomplishment and responses through verbal and non-verbal interactions from teachers gave children feedback on what they were doing, names and affirms their efforts, celebrates their progress and achievements, all these help children to learn. The findings also indicated that teachers used strategies such as appropriate questioning, responding and feedback with some of the interactions evident in the increase or decrease intonation, waiting-time or pausing and turn-taking process which was identified through the use of the Conversational Analysis Transcription Convention. This reveals how the interactions were being co-constructed to enhance the children's learning.
\end{abstract}

Keywords: teacher-child interaction, Mathematic activity, preschool

\section{INTRODUCTION}

When child development and mathematics are mentioned together, Jean Piaget and Lev Vygotsky come to mind. (Jackman, 2005). Jean Piaget pioneered the study of children's thinking and described how each child creates his/her own mental images or knowledge of the world. Piaget's LogicalMathematical knowledge describes the type of relationships individual constructs in order to make sense out of the world and to organize information, such as classification, counting, and comparing (Charlesworth \& Lind, 2003). Vygotsky also studied children's thinking and contributed significant insight into the way we learn from those around us, especially those who have more skills. Vygotsky believed that we develop ways of cooperating and communicating (Charlesworth \& Lind, 2003).
'Tell me mathematics, and I will forget; Show me mathematics and I may remember; involve me ... and I will understand mathematics' (William quoted in Furner \& Berman, 2009). This definitely triggers thoughts of teachers who teach Mathematics. Educators, teachers, practitioners and researchers in Early Childhood Education understand the importance of this interaction during any particular activities as this will enhance the children's learning. Children who experienced sensitive and responsive interactions are more likely to demonstrate increase social competence, and stronger academic skills (Curby, Brock \& Hamre, 2013; Hamre, Downer, Jamil \& Pianta, 2012). The quality of the interactions between teacher and child has shown to be a leading indicator of an effective early childhood program (Mashburn et al., 2008). Importantly, the quality of these interactions depends on the skills in 
listening, responding or asking questions or even showing gestures in any activities in class with the preschoolers.

In recent years, efforts to characterize preschool classroom quality have focused increasingly on classroom process or interactions that the children experience with their environment, with their peers, and with their teachers (Hamre \& Pianta, 2007). Two dimensions of teacher-child interactions that have been linked to positive outcomes for young children are those related to teachers' emotional supportiveness including relationships and sensitivity to children's needs and those related to instructions, including teachers' use of language to scaffold more complex skills associated with gains in language and social skills (Burchinal et al., 2008; Curby et al).

Early year's pedagogical practice believes that supporting children's learning through play that is responsive to children's interest and motivations helps in their learning. It involves a fluidity in the pace and timing of the experiences and interactions, and commitment. The question, what exactly is happening during the interactions? What are the most effective ways to interact with early years' children? Young children learn and develop through being active in the world or their own environment. They explore, examine, observe and experience their world through all their senses. Children learn through conversation, interaction and listening. Conversation, interaction and thinking enable children to develop their learning and understanding, acquire new skills and enhance normal progress development.

When teachers interact with students in a positive way (individually, in small groups or whole class), these interactions have potential to provide children with support for their learning (Pianta, La Paro, \& Hamre 2008). Interaction is a kind of action that occurs as two or more objects have an effect upon one another. Interactions can be verbal and non-verbal communications. Interactions achieve two important goals. They allow teachers to build and deepen relationships with each child, develop meaningful and lasting learning, and build strong personal relationship between teachers and children.

In order for interactions to be effective, it requires a range of interactive strategies that need to be used appropriately to support children's learning and development. There are a few that can be used with early years for example; saying, discussing, pondering, questioning, answering, modelling, direct teaching, waiting time or responding to the children's question and even through non-verbal communications such as gestures. In addition, having teaching aids or illustrations during class activities in school further develop interest in children to be involved. This will create a positive interactive communication verbal or non-verbal alongside with the children as learning progress or skills takes place.

The question of why Math matters? Today, those who are involved in mathematics education and research believed that the reason for learning mathematics will help in many phases of later lives. It is not about correcting every error, instead, it encourages investigation, feedback, inquiries and finding solutions through constructing their own knowledge. Children learn and develop by interacting with others even in mathematic activities. Teachers who are respectful listeners and keen observers, who are prepared to negotiate, who change their practice, and who make meaning with children are those who are most responsive to them. Their interactions promote children's learning and development and help children to reach their full potential. Teachers play a key role in supporting interactions with children, as their interactions build and deepen relationships with each child.

Meaningful and lasting learning depends on this strong personal relationship between them. When teacher uses interesting language, ask questions, help children make connections, the teacher engages their curiosity and extend their thinking.

\section{METHODOLOGY}

The study used qualitative method that is observation. The purpose of study is to examine the interactions between preschool teachers and children aged six during Mathematic activities in class. The data was collected using video recording during the Mathematic activities in class. The sampling technique used was purposeful sampling of children and their Mathematic teachers from each class. One class (class 1) has eight (8) children and the other (class 2) has 6 children aged six years old. The observations were done during four (4) mornings between $10.00 \mathrm{am}-11.00$ am for each class. The activities were:

a. The First ( $\left.1^{\text {st }}\right)$ Mathematic Activity (class 1) The teacher taught about concept of tall and short and measurements; comparing heights. The objective was to differentiate between tall and short.

b. The Second ( $\left.2^{\text {nd }}\right)$ Mathematic Activity (class 1 ) It was the continuation on learning counting; 0 to 21 , learning about numbers and to recognized numbers. It was the introduction of 
number 21 . The activity used number cards. The objectives were to recognize number 21 and number sequence from 1 to 21 .

c. The Third ( $\left.3^{\text {rd }}\right)$ Mathematic Activity (class 2) It was one to one correspondence of the number and the quantity. The activity used number cards and magnetic buttons.

d. The Forth $\left(4^{\text {th }}\right)$ Mathematic Activity (class 2) The activity was on the introduction on the concept of addition by using number cards, toy cars and buttons. Towards the end of the activity, the teacher reinforced the concept with the arrangement of number sequence, using number cards.

\section{RESULTS AND DISCUSSION}

Seven main categories emerged from the research data: Acknowledgment, Response, Expression, Encouragement, Clarity of Question, Timing and Assistance.

\subsection{Acknowledgement}

The sub-categories are motivating, acknowledge and compliment that were shown by the teacher. It is shown through the exclamations during the interaction such as 'Ah', Aha, Eh, Phew, Ok or Okay and mmm' that represents the acknowledgement by the teacher. These exclamations represent an expression of agreement or surprise and pleasure to the children during the interaction. The children stop or explore, to think and rethink in their mathematics activities conducted in class. These acknowledgements such as 'Aha, Ah, $\mathrm{O}$ or even $\mathrm{Ok}$ ' represent the interactive conversation between teacher-children as the children think, rethink or recall their teacher's responses to their answers or questions.

'Ah! Like your brother'. First, he is short then he will become tall.

(The child will imagine his brother will become tall, as he gets older)

'O, clever Adam', said the teacher when Adam is able to find number card 10.

(The teacher quite surprise and recognized of Adam achievement)

Upkrory answered 19. Then the teacher asked, 'Ok, after 19?'

(Think or recall, what is the next number?)
The teacher praised Arfan:

'Clever Arfan and give a clap to Arfan' (Arfan is able to find number card 5).

'Let him find number 9' the teacher is giving some motivation so he can try to do the activity on his own.

Compliment is one of the important issues in children's learning process. Children are so excited when complimented by their teacher. Compliments make a child feels great, feels approved, feels wanted and it boost a positive performance. It is a great feeling. For example; in the $1^{\text {st }}$ activity, the teacher said,

'Clap hands for Ain', when she is able to answer number 15 and to find the number card 15.

\subsection{Responses}

The category 'Responses' consist of sub-categories as shown by 'Teacher Self Response, Responding and Reinforcement'. Response is significant as it will enable the teacher to interact more with the children.

The Teacher Self Response does not contribute much to the learning process during the mathematics activity. In the four activities conducted, the teacher self- response is too much. The teacher did not give much opportunity for the children to think, to answer or even to respond to the teacher's question. The teacher seems to 'hijack' the activities in almost all of the four mathematics activities. It does not matter if the answer is not correct but at least the child tries. The children need all the opportunities to give them a chance to answer, to respond, or to question back.

In activity 1 , the teacher asked, what is the next number?

She self-response, 'Number 10' or who has the next number after 1, 2', the teacher selfresponse, '3' and 'Ok, after number 3? Look at your card, after number 3, number 4.

In activity 2, as Isha puts the $1^{\text {st }}$ button, the teacher said ' 1 ', then Isha puts the $2^{\text {nd }}$ button and the teacher said '2' and then ' 3 ' and '4'. This is also self-response as the child or other children do not have the opportunity to count. The teacher counted the number by herself. 
Reinforcing what has been learnt or achieved is another good way of teacher-child interaction in knowing whether the child is able to grasp what has been taught. The teacher can also reinforce by asking a question twice, for example in activity 1 :

1. 'Can you see the difference?

2. 'Aqil, is there any difference?'

Reinforcing can also be done by repeating what the child has replied or said. This is to make sure that the child understands what is being taught or has been shown to him/her.

Ain said, ' 15 ' then the teacher said, ' 15 ' Responding to the child by using the correct and acceptable verbal and non-verbal communication is important. The teacher is a role model to the child. For example,

Ain said 'I have seen my father's working place'. The teacher responded, 'Ah, her father's working place, the building is tall'

According to Durden and Dangel (2008), the qualities of interaction are characterized by the teacher listening to, repeating the child's talk, modelling complete thoughts and compliments children on their efforts.

\subsection{Expression}

An expression can be seen in verbal and non-verbal communication. The expression of a speech can be identified by the different intonations, as in increase or decrease intonation (Sack, Schegolff, \& Jefferson, 1974) and the symbol of increase intonation 4 and decrease intonation $\downarrow$. The difference in intonation may help in children's learning.

The teacher wanted to emphasize the difference between heights of tall and short by using different intonations to make children aware of it. The intonation may represent a better picture.

Activity 1: What things are tall $\mathbf{\uparrow}$ and what things are short?

Activity 2: Is it correct, children? As she pointed to the number card.

Activity 3: How many is 6 added to 1? $\uparrow$

Activity 4: 7! Is it correct? $\mathbf{4}$

Expression through non-verbal communication is about gestures can either be symbolic or nonspecific. Symbolic such as waves, thumbs up or nod of the head while non-specific gestures such as 'talking' with hands and facial expression or gaze. This is important in providing feedback and responds to the children and explaining further for a better understanding.
Non-specific gestures can be seen; when the teacher is explaining to the children and says,

'Some things are short (as the teacher showed her hand low)

'...will grow tall, tall, tall (as the teacher moved her hand high up)

'Have you seen a building?' (As the teacher showed her hands high up)

'There is a difference between tall and short' (As the teacher explained and showed movement of her hands up and down to the children (in $1^{\text {st }}$ activity)

Examples of symbolic gestures as in $3^{\text {rd }}$ activity:

'Misha, can you help to do number 6?' (The teacher nodded her head)

\subsection{Encouragement}

Encouragement is the next category with a subcategory as in participation. When the teacher used interesting language and asks questions, this help children make connections as well as the teacher engaged the children's curiosity to participate in the activity. It can be in a sentence, word or question for the children to participate. This practice will help the teacher to evaluate the children's understanding of their learning in an activity.

$1^{\text {st }}$ activity, the teacher asked the children,

'Who would like to be short?' (As she showed gesture of her hands low)

'Me, me,' said Iman. Iman excitedly responded with the encouragement given by the teacher

'Can we count together? Asked the teacher.

'Can' respond the children.

'Let us count together' said the teacher. All the children counted together from 1 to 21 


\subsection{Clarity of Questions}

The sub-categories are rephrasing of questions, statements or sentences. If the child does not understand and is confused by the questions, the teacher will change to another question or sentence to enable the child to understand or answer her questions during the activity.

The underline sentences or questions represent the second attempt by the teacher to clarify the questions or sentences.

In the $3^{\text {rd }}$ activity:

'Adam, you may choose a number', said the teacher.

Adam looked at the numbers in the container. 'Which number do you want and placed here at the easel?' said the teacher?

In the $4^{\text {th }}$ activity:

How many is '2 added to 4?' the teacher questioned the children.

How many is ' 2 blue cars added to 4 green buttons?

\subsection{Timing}

'Is there any waiting time' - pausing in the interactions between the teacher and the child during the learning process. This happens between the questions asked and the response from the child. This category is to confirm that waiting time or pausing can contribute to the construction of the children's understanding in the mathematics activities (Table 1). The teacher waited to give a chance for the children to respond to her questions or statements. This is to give the children time to think or to recall or reflect what has been taught or what is accomplished.

Table 1. Timing between the question and respond

\begin{tabular}{|l|l|}
\hline Activity & $\begin{array}{l}\text { How many seconds does the teacher } \\
\text { waited for the child to respond? }\end{array}$ \\
\hline Number 1 & $\begin{array}{l}\text { 'Which building is the tallest that you } \\
\text { have seen?' asked the teacher. (4.8) } \\
\text { 'Hotel', replied Akil. }\end{array}$ \\
\hline Number 3 & $\begin{array}{l}\text { The teacher then says 3 added to 2 is? } \\
\text { Who knows the answer, 3 added to 2? } \\
\text { (3.8) } \\
\text { '5', replied Najwah. }\end{array}$ \\
\hline
\end{tabular}

Turn taking is also a sub-category of timing. The turn taking is the immediate respond by the child. It is between the teacher and the child with an immediate reply. Such turn taking interaction process helps in the child's learning and is able to contribute to his/her learning as well as the opportunity for improvement. It is more of 'Questions and Answers or Response to the question'.

In the 4th activity, the teacher showed number card 1 and asked the children,

'How many do we need now?

Najwah replied ' 1 ' or

'Now, how many cars do we have?

'6', replied all the children.

In the $2^{\text {nd }}$ activity,

'Syamil, what number is that?' asked the teacher.

Syamil replied, 'Number 7'.

‘After number 8?' asked the teacher.

'9', answered Syamil.

\subsection{Assistance}

What were the teaching aids used by the teacher to incorporated in their teaching that enable interactions to occur with the children in class during the mathematics activities? The subcategories involved are teaching aids and guidance/guiding. Teaching aids are the materials used to assist in the children's learning and guiding in the form of helping out or assisting or giving clues in their learning. The children will be able to visualize and touched the materials. The teachers did use teaching aids in their interactions with the children and even gave clues to assist the children to understand better. The teachers used number cards, small model cars, different height self-made trees, different height vases, and magnetic colored buttons. In the $1^{\text {st }}$ activity, the teacher used different size trees and vases according to height and size to educate the child regarding 'tall and short'.

In the $2^{\text {nd }}$ activity the teacher used number cards from 1 to 21 and pasted it on the easel. 
'Together, the children started counting 1234 5678910 . As the children pronounce the number loudly, the teacher used her finger to show the number and say it together but softly.

\section{CONCLUSIONS}

As a conclusion, the guided mathematics activities did accomplish the learning process with some of the children. The children learned about numbers, counting, recognizing, and measurement in comparing different heights, understanding the concept of addition and sequencing numbers. The children too had the opportunity to see and used the teaching aids for a better understanding.

How do the interactions during the Mathematics activities help in the process of learning Mathematics? The findings reported only the teacher's interactions with the children in the process of learning mathematics and providing opportunity for children to engage in the interactions. The findings indicate that the teacher's interaction is significant in the learning process during the Mathematics activities in class. According to Piaget's Cognitive theory, active involvement through direct experiences with physical world helps children develop intelligence. Vygotsky's theory further identifies the Zone of Proximal Development as a platform for the learning process which is achieved through interactions with adults. (O’Connor, 1998 \& Vygotsky, 1962.)

\section{ACKNOWLEDGEMENTS}

I would like to express my gratitude to Haji Abdul Razak, my husband for being so supportive in my research. Dr. Zahyah Hanafi had encouraged and motivated me along the way. I would like to thank the management at the City University College of Science and Technology for allowing me to present this paper at the conference.

\section{REFERENCES}

Berk, L.E. (2006). “Child Development $7^{\text {th }}$ edition”. Boston: Allyn \& Bacon.

Curby, W. T. (2009). Teacher-Child Interactions \& Children's Achievement Trajectories across Kindergarten \& First Grade. Journal of Educational Psychology, 101 (4), 912-925.

Durden, T., \& Dangel, J. R. (2008). "Teacher-Involved Conversations with Young Children during Small Group activity". DigitalCommons@University of Nebraska.

http://digitalcommons.unl.edu/cyfsfacpub/18/
Hamre, Downer, Jamil \& Pianta. (2012). "Evidence for General and Domain-specific elements of TeacherChild Interactions: Associations with Preschool Children's Development". Willey online Library.

Krogh, S., \& Morehouse, P. (2009). "The Early Childhood Curriculum”. London: Routledge Taylor \& Francis Group.

Mashburn AJ, Pianta RC, Hamre Bk, Downer Jt, Barbarin OA, Bryant D, Burchinal M, Early DM, Howes C. (2008). "Measures of Classroom Quality in Prekindergarten and Children's Development of Academic, Language, and Social Skills".

Mukherji, P., \& Albon, D. (2010). "Research methods in Early Childhood: An Introductory Guide”. London, Britain. Sage Publications Ltd.

Munro, S. (2008, Feb.). Opportunity Lies in Teacher-Child Interaction. The Education Digest, 73(6), 46-48.

Piaget's Theory of Cognitive Development. http://www.study.com/academy/lesson/piagetstheory-of-cognitive-development

Sack, Schegolff \& Jefferson. (1974). A simplest systematics for the organization of turn-taking for conversation, Language, 50, 696-735.

Smith, T. (1994). Interactions in the Early Childhood Classroom. Early Care and Education Training and Consulting. http://tymthetrainer.com/omages/Interactions.pdf

Young, H., \& Reifel, S. (2011). Promoting Children's Communication: A Kindergarten Teacher's Conception \& Practice of Effective Mathematics Instruction. Journal of Research in Childhood Education, 25, 194-210.

Zepeda, J. S., (2009). "Informal Classroom Observation $2^{\text {nd }}$ edition”. New York, Hypertext books and Journal services. 